\section{Discussion}

Although we used two methods to determine acetylator status, Evans ${ }^{6}$ had shown that these gave identical separation. We also felt that it was valid to compare our data with his population survey data. In our series slow acetylators were less common among diabetics who had had the disease for at least 10 years without developing neuropathy than among those with neuropathy or the normal population. An increased proportion of fast acetylators was reported ${ }^{7}$ in a series of unselected diabetics, but in our series the preponderance of fast acetylators was seen only in the group without neuropathy. The difference between the two groups of diabetics makes it unlikely that this preponderance was due merely to linkage between acetylator and putative diabetic genes. Nor could there be a relation with the histocompatibility genes, since there was a similar distribution of acetylator phenotypes between patients with juvenile-onset and maturity-onset diabetes, yet HLA-B8, BW15, and BW18 are increased in frequency only in juvenile-onset diabetes. ${ }^{*}$

The association between freedom from neuropathy and fast acetylator phenotype was similar to that found in patients taking isoniazid." In isoniazid neuropathy, however, axonal degeneration is the main pathological lesion, ${ }^{9}$ whereas in diabetes segmental demyelination is usually seen. ${ }^{10}$ Hence the two neuropathies are unlikely to have a common aetiology, such as pyridoxine deficiency. Recently, however, axonal degeneration was reported in experimental diabetic neuropathy. ${ }^{11}$
Our findings suggest that genetic factors unrelated to the diabetic diathesis may interact with the metabolic abnormality of diabetes to determine whether a patient develops a neuropathy. Clearly the impaired ability to acetylate may have aetiological significance.

We thank Drs F J Flint, D R Cullen, and J R Hearnshaw for permission to study their patients, and Stephen Humphries for technical help.

\section{References}

${ }^{1}$ Stowers, J M, in Complications of Diabetes, ed H Keen and R J Jarret, p 1. London, Arnold, 1975

2 Thomas, P K, and Ward J D, in Complications of Diabetes, ed $\mathrm{H}$ Keen and R J Jarret, p 151. London, Arnold, 1975.

${ }^{3}$ Oakley, W G, et al, Quarterly fournal of Medicine, 1974, 43, 145.

${ }^{4}$ Evans, D A P, Manley, K A, and McKusick, V A, British Medical fournal, 1960, 2, 485.

${ }^{5}$ Devadatta, S, et al, Bulletin of the World Health Organisation, 1960, 23, 587.

${ }^{6}$ Evans, D A P, fournal of Medical Genetics, 1969, 6, 405.

Mattila, M K, and Tiitinen, H, Annals Medicinae Experimentalis et Biologiae Fenniae, 1967, 45, 423.

${ }^{8}$ Cudworth, A G, British Fournal of Hospital Medicine, 1976, 16, 207.

- Ochoa, J, Brain, 1970, 93, 831

${ }^{10}$ Chopra, J S, and Fannin, T, fournal of Pathology, 1971, 104, 175.

11 Jakobsen, J, Diabetologia, 1976, 12, 400.

\title{
BCG and vole bacillus vaccines in the prevention of tuberculosis in adolescence and early adult life
}

\section{Final report to the Medical Research Council}

\author{
P D'ARCY HART, IAN SUTHERLAND
}

British Medical fournal, 1977, 2, 293-295

\section{Summary}

The Medical Research Council's trial of BCG and vole bacillus vaccines in the prevention of tuberculosis in Great Britain has ended after 20 years' follow-up of the 54239 participants, who were aged 14 to 15 years when they entered the trial in 1950-2. Participants who were tuberculin positive on entry were left unvaccinated; those who were tuberculin negative were allocated at random to an unvaccinated or to a vaccinated group.

The protective efficacy of each of the two vaccines, among those initially tuberculin negative, was $84 \%$ during the first five years, and gradually decreased, averaging $77 \%$ for each vaccine over the whole period. The incidence of tuberculosis decreased substantially in all groups during the trial, however, and of the total of 610 cases of tuberculosis only 27 developed between

MRC Statistical Research and Services Unit, University College Hospital Medical School, London WC1E 6AS

P D'ARCY HART, MD, FRCP, formerly director, MRC Tuberculosis Research Unit, and chairman, MRC Tuberculosis Vaccines Clinical Trials Committee (present address: National Institute for Medical Research, London)

IAN SUTHERLAND, MA, DPHIL, director, MRC Statistical Research and Services Unit (formerly secretary, MRC Tuberculosis Vaccines Clinical Trials Committee)
15 and 20 years. Thus we cannot make a reliable assessment of efficacy during this final period.

The prevalence and incidence of tuberculosis in Great Britain have decreased radically since this trial began. The expected benefit from large-scale BCG-vaccination of children is now far less, and may decrease further if the incidence of tuberculosis continues to decline.

\section{Introduction}

In 1950 the Medical Research Council started a controlled clinical trial of the effects of BCG and vole bacillus vaccines during adolescence and early adult life. Over 50000 children of both sexes, nearly all aged 14 to $15 \frac{1}{2}$ years on entry, participated. All were initially free from both active tuberculosis and known contact with the disease at home and originally lived in urban or suburban areas in or near north London, Birmingham, and Manchester. Those with negative reactions to tuberculin on entry were vaccinated with BCG or vole bacillus vaccine or left unvaccinated, according to a method of random allocation. All the participants, including those who initially had positive reactions to tuberculin, were followed up to discover the cases of tuberculosis that occurred among them.

The four reports already published ${ }^{1-4}$ gave further details of the trial and showed that the two vaccines conferred substantial protection against tuberculosis for 15 years after vaccination. This paper is intended only as a supplement to those reports; it extends the information on protection up to 20 years after vaccination, at which stage the trial ended. 
Cases of tuberculosis developing 15 to 20 years after entry

Information on definite and suspected cases of tuberculosis in the trial participants continued to be obtained from regular returns made by chest clinics and medical officers of health throughout Great Britain. Experience had shown that the annual postal inquiries to individual participants, which had been made in parallel with the chest clinic and local health authority returns for the previous seven years, had detected only a few cases of tuberculosis (all non-respiratory) that were not included in the returns-about one case a year. ${ }^{4}$ The cases of respiratory tuberculosis recorded among trial participants from 15 to 20 years are thus believed to represent a complete total, though a very few cases of non-respiratory tuberculosis may have escaped notice.

As before, the case records of all patients with tuberculosis or suspected tuberculosis or with a persistent pulmonary radiographic abnormality which came to notice during the period were submitted to an independent assessor who was kept unaware of the results of any tuberculin tests and of whether or not vaccination had been performed. The assessment was made from the series of radiographs and the findings of all the clinical and other examinations of the patient, both on diagnosis and subsequently.

Twenty-seven participants were found to have developed tuberculosis from 15 to 20 years after entry. Of these 17 had pulmonary tuberculosis and two had pleural effusions without evidence of pulmonary tuberculosis. The eight participants with non-respiratory disease comprised five with genitourinary tuberculosis, two with tuberculous adenitis, and one with a tuberculous ethmoid.

The 54239 participants were automatically classified on entry, according to their initial tuberculin test results and the random allocation of vaccination, ${ }^{1}$ into the groups listed in table I. From 15 to 20 years five cases of tuberculosis occurred in the tuberculin negative, unvaccinated group, six in the BCG-vaccinated group, and one in the vole-bacillus-vaccinated group. Among those who initially gave a positive reaction to tuberculin (and who were not vaccinated), 12 cases occurred in those with positive reactions to 3 tuberculin units (TU) and three among those with weaker positive reactions (negative to 3 TU but positive to $100 \mathrm{TU}$ ).

\section{Cases of tuberculosis during the 20 years}

Table I shows the numbers of cases of tuberculosis developing in the various trial groups in successive two and a half year periods since entry and the progressive aging of the trial cohort as the follow-up proceeded. In all, 610 cases of tuberculosis were discovered during the 20 years -248 among those who initially gave a negative reaction to tuberculin and who were left unvaccinated, 88 in the two vaccinated groups, and 274 among those who were initially tuberculin positive. Altogether 361 cases developed in the first five years after entry, 158 from 5 to 10 years, 64 from 10 to 15 years, and 27 from 15 to 20 years. Thus the incidence of tuberculosis decreased substantially in the trial population between the ages of about 15 and 35, during 1951-71. The decrease in the numbers of cases in the negative unvaccinated group was particularly steep. After an initial rise the number of cases approximately halved every two and a half years.

The incidence of each specific form of the disease, except for genito- urinary tuberculosis, decreased substantially during the first 15 years. ${ }^{4}$ The numbers of cases of genitourinary tuberculosis in the four fiveyear periods (not separately tabulated) were $3,5,14$, and 5 , and of these $3,4,9$, and 2 respectively occurred among participants who were already positive to $3 \mathrm{TU}$ on entry to the trial. The incidence of this form of tuberculosis thus fell from the peak which it showed 10 to 15 years after entry-that is, when the participants were aged 25-29 years.

\section{Incidence of tuberculosis during the 20 years}

The annual incidence of tuberculosis in each of the trial groups is shown in table II. For the whole period the average annual incidence was 0.98 per 1000 in the tuberculin negative unvaccinated group and 0.23 per 1000 in each vaccinated group. The protective efficacy (the percentage reduction in incidence in the vaccinated group compared with that in the randomly established unvaccinated group) was thus $77 \%$ for each of the two vaccines. In those participants with large positive reactions to $3 \mathrm{TU}$ initially ( $15 \mathrm{~mm}$ or more) the average annual incidence during the period was 1.04 per 1000 , which was substantially larger than the incidence of 0.45 per 1000 that was found both in those with smaller positive reactions to $3 \mathrm{TU}(5-14 \mathrm{~mm})$ and in those who were positive only to $100 \mathrm{TU}$.

Table II also shows the incidence in each trial group in successive five-year periods. The incidences in the tuberculin-negative unvaccinated group were $2.50,1.06,0.26$, and 0.08 per 1000 , compared with $0.40,0.34,0.09$, and 0.07 respectively for the two vaccinated groups combined. The protective efficacy of vaccination thus showed a progressive decrease in successive five-year periods. The efficacy of $9 \%$ from 15 to 20 years after vaccination cannot be regarded as a precise estimate, being based on totals of only five cases of tuberculosis in the negative unvaccinated group and seven in the vaccinated groups combined. The downward trend in protective efficacy during the trial was, however, significant at the $1 \%$ level for both vaccines combined and for BCG vaccine separately.

TABLE II-Annual incidence of tuberculosis per 1000 participants and protective efficacy of vaccination according to interval since vaccination

\begin{tabular}{|c|c|c|c|c|c|}
\hline \multirow[t]{2}{*}{ Trial group } & \multicolumn{5}{|c|}{$\begin{array}{l}\text { Annual incidence per } 1000 \text { participants* } \\
\text { in each interval (in years) }\end{array}$} \\
\hline & $0-20$ & $0-5$ & $5-10$ & $10-15$ & $15-20$ \\
\hline $\begin{array}{l}\text { Negative, unvaccinated } \\
\text { Negative, BCG vaccinated } \\
\text { Negative, vole-bacillus } \\
\text { vaccinated }\end{array}$ & $\begin{array}{l}0.98 \\
0.23 \\
0.23\end{array}$ & $\begin{array}{l}2.50 \\
0.40 \\
0.41\end{array}$ & $\begin{array}{l}1.06 \\
0.33 \\
0.38\end{array}$ & $\begin{array}{l}0 \cdot 26 \\
0 \cdot 10 \\
0 \cdot 07\end{array}$ & $\begin{array}{l}0.08 \\
0.09 \\
0.03\end{array}$ \\
\hline $\begin{array}{l}\text { Positive to } 3 \mathrm{TU}: \\
\text { Induration } 15 \mathrm{~mm} \\
\text { Induration } 5-14 \mathrm{~mm} \\
\text { Positive only to } 100 \mathrm{TU}\end{array}$ & $\begin{array}{l}1 \cdot 04 \\
0.45 \\
0.45\end{array}$ & $\begin{array}{l}2 \cdot 79 \\
0.82 \\
1 \cdot 00\end{array}$ & $\begin{array}{l}0 \cdot 71 \\
0 \cdot 43 \\
0 \cdot 49\end{array}$ & $\begin{array}{l}0 \cdot 48 \\
0 \cdot 37 \\
0 \cdot 23\end{array}$ & $\begin{array}{l}0 \cdot 15 \\
0 \cdot 16 \\
0 \cdot 10\end{array}$ \\
\hline $\begin{array}{l}\text { Protective efficacy }\left({ }^{\circ} 0\right) \\
\text { BCG } \\
\text { Vole bacillus } \\
\text { Both }\end{array}$ & $\begin{array}{l}77 \\
77 \\
77\end{array}$ & $\begin{array}{l}84 \\
84 \\
84\end{array}$ & $\begin{array}{l}69 \\
64 \\
68\end{array}$ & $\begin{array}{c}59 \\
(73)+ \\
63\end{array}$ & $\begin{array}{r}(-12) \\
(56) \\
(9)\end{array}$ \\
\hline
\end{tabular}

*After allowing for removals from population at risk due to death or contracting + Parentheses indicate a protective efficacy based on a total of 20 cases of tuberculosis or less.

TABLE I-Incidence of tuberculosis in trial participants according to interval between entry and earliest radiographic or clinical manifestation (the starting point) of disease

\begin{tabular}{|c|c|c|c|c|c|c|c|c|c|c|}
\hline \multirow{3}{*}{ Trial group } & \multirow{3}{*}{$\begin{array}{c}\text { No of } \\
\text { participants }\end{array}$} & & \multicolumn{8}{|c|}{ No of cases of tuberculosis } \\
\hline & & \multirow{2}{*}{ Total } & \multicolumn{8}{|c|}{ Interval in years } \\
\hline & & & $0-2 \frac{1}{2}$ & $2 !-5$ & $5-7 !$ & $7 \frac{1}{2}-10$ & $10-12 !$ & $12 !-15$ & $15-17 !$ & $17 !-20$ \\
\hline $\begin{array}{l}\text { Negative, unvaccinated } \\
\text { Negative, BCG vaccinated } \\
\text { Negative, vole-bacillus-vaccinated }\end{array}$ & $\begin{array}{r}12867 \\
13598 \\
5817\end{array}$ & $\begin{array}{r}248 \\
62 \\
26\end{array}$ & $\begin{array}{r}68 \\
14 \\
7\end{array}$ & $\begin{array}{r}92 \\
13 \\
5\end{array}$ & $\begin{array}{r}41 \\
13 \\
6\end{array}$ & $\begin{array}{r}26 \\
9 \\
5\end{array}$ & $\begin{array}{r}11 \\
2 \\
1\end{array}$ & $\begin{array}{l}5 \\
5 \\
1\end{array}$ & $\begin{array}{l}2 \\
3 \\
0\end{array}$ & $\begin{array}{l}3 \\
3 \\
1\end{array}$ \\
\hline $\begin{array}{l}\text { Positive to } 3 \mathrm{TU} \\
\text { Induration } \geqslant 15 \mathrm{~mm} \\
\text { Induration } 5-14 \mathrm{~mm} \\
\text { Positive only to } 100 \mathrm{TU}\end{array}$ & $\begin{array}{l}6866 \\
8838 \\
6253 \\
\end{array}$ & $\begin{array}{r}140 \\
78 \\
56 \\
\end{array}$ & $\begin{array}{l}64 \\
17 \\
12 \\
\end{array}$ & $\begin{array}{l}31 \\
19 \\
19 \\
\end{array}$ & $\begin{array}{r}17 \\
12 \\
9 \\
\end{array}$ & $\begin{array}{l}7 \\
7 \\
6 \\
\end{array}$ & $\begin{array}{r}11 \\
9 \\
1 \\
\end{array}$ & $\begin{array}{l}5 \\
7 \\
6 \\
\end{array}$ & $\begin{array}{l}5 \\
3 \\
1 \\
\end{array}$ & $\begin{array}{l}0 \\
4 \\
2 \\
\end{array}$ \\
\hline All groups & 54239 & 610 & 182 & 179 & 98 & 60 & 35 & 29 & 14 & 13 \\
\hline \multicolumn{3}{|c|}{ Average age of trial cohort at beginning of the interval (years) } & $14 \cdot 7$ & $17 \cdot 2$ & $19 \cdot 7$ & $22 \cdot 2$ & $24 \cdot 7$ & $27 \cdot 2$ & $29 \cdot 7$ & $32 \cdot 2$ \\
\hline \multicolumn{3}{|c|}{ Average calendar date at beginning of follow-up interval } & 1951.9* & $1954 \cdot 4$ & $1956 \cdot 9$ & $1959 \cdot 4$ & $1961 \cdot 9$ & $1964 \cdot 4$ & $1966 \cdot 9$ & $1969 \cdot 4$ \\
\hline
\end{tabular}

*That is, nine-tenths of a year after the beginning of 1951. 
Among those with large positive reactions to $3 \mathrm{TU}$ initially, the incidences of cases of tuberculosis in successive five-year periods were $2.79,0.71,0.48$, and 0.15 per 1000 participants. The high early incidence of tuberculosis in this group and the subsequent decrease were noted and discussed in the second report. ${ }^{2}$ Among those with smaller positive reactions to $3 \mathrm{TU}$ and those positive only to $100 \mathrm{TU}$ the incidence during the first five years was about a third of that in subjects with large positive reactions to $3 \mathrm{TU}$ and remained lower, though the differences diminished considerably. In the final five-year period the incidence was very low in all the three initially positive groups, though still higher than in the three initially negative groups.

\section{Discussion}

A full commentary on the results of the trial during the first 15 years was included in the fourth report. ${ }^{+}$We present here a postscript to that commentary, in the light of the figures during the whole 20-year period.

This trial has shown clearly that in Great Britain the use of BCG vaccine and vole bacillus vaccine, given as artificial immunising agents in 1950-2 to adolescents aged about 15 years, led to a substantial reduction in the incidence of tuberculosis which extended over the whole of the ensuing 20 years. The reduction, among those who were uninfected with tubercle bacilli initially, was about 75 to $80^{\circ}{ }^{\circ}$, with each vaccine.

There was a decrease in the incidence of tuberculosis during the 20 years in all trial groups, especially among those who initially gave negative results to a tuberculin test. In this group the peak incidence occurred two and a half to five years after entry-that is, in about 1955, when the participants were aged 18 years. With the diminishing risk of tuberculosis infection and the increasing age of the cohort the number of cases in this trial group approximately halved in each successive two and a half year period. If this trend has continued beyond 20 years then only one or at most two cases of tuberculosis will have developed among more than 12000 initially uninfected and unvaccinated subjects from 20 to 25 years after entry to the trial. The consinuance of the trial beyond 20 years would thus have provided rirtually no more information on the benefit from tuberculosis raccination, so the trial was ended.

The gradual convergence of the tuberculosis rates in the negative unvaccinated and the vaccinated groups as the trial proceeded has been confirmed by the figures in the present report. The reasons were discussed fully previously. ${ }^{3}{ }^{4}$ Briefly, the convergence could have resulted from (a) a gradual increase in the level of resistance in the unvaccinated group (relative to the vaccinated groups) as a result of natural infections by tubercle bacilli and other mycobacteria, or the withdrawal of those particularly susceptible because they contracted tuberculosis; $(b)$ a gradual decrease in the level of resistance in the vaccinated groups (relative to the unvaccinated group) as a result of a waning in the efficacy of the vaccines; or $(c)$ the operation of both effects. Whatever the full explanation for the convergence may be, the very considerable initial benefit conferred by vaccination has clearly not been maintained. It is unfortunate that the information now available from 15 to 20 years is too limited to provide a reliable estimate of the extent of the benefit during this final period.

Since the publication of the fourth report 20-year reports on two of the United States Public Health Service trials of BCG vaccination have appeared. ${ }^{5}$ In North America also the already low incidence of tuberculosis has decreased further, and these reports do not substantially alter the previous findings. There have been several commentaries ${ }^{4-9}$ on the reasons for the wide differences in the efficacy of BCG vaccination found in these and other trials.

In Great Britain surveillance studies ${ }^{1011}$ have been made of the efficacy of BCG vaccination in the national scheme for children aged 10-13 years. These studies were not controlled trials but were comparisons of the incidence of tuberculosis in subjects given BCG vaccine in the national scheme and in those who did not participate. They provided supporting evidence of the continuing efficacy of BCG vaccine in preventing tuberculosis in Great Britain, notwithstanding the variations found in other parts of the world. In particular, they showed the high protective efficacy in this country of vaccine from the Glaxo strain of BCG (which was derived from the Copenhagen strain of BCG used in the Medical Research Council trial); the Glaxo strain is now used routinely for BCG vaccination in this country and in many others.

Nevertheless, the expected benefit to the section of the community covered by a tuberculosis vaccination scheme (in adolescence or at any other age) does not depend solely on the efficacy of the vaccine in those who are vaccinated. The benefit may be expressed as the absolute reduction in incidence of tuberculosis in the entire population group considered for vaccination, as a result of vaccinating those who are eligible. This is the product of three factors ${ }^{4}$ : $(a)$ the protective efficacy of the vaccine among those who are eligible-that is, those who give a negative reaction to tuberculin; $(b)$ the expected annual incidence of tuberculosis in those eligible if they were left unvaccinated; and $(c)$ the proportion of the population who are eligible. The second factor is the most important determinant of the degree of expected benefit.

The prevalence and incidence of tuberculosis in this country have decreased radically since the national scheme for BCG vaccination at the age of 10-13 years was introduced in 1953 . The decreasing risk of tuberculous infection has led to an increase in the proportion of children who are eligible to benefit, but this has been more than offset by the very substantial decrease in the incidence of tuberculosis in adolescents and young adults. Thus despite the continuing high efficacy of BCG vaccination, the benefit to be expected from the national scheme is now far less than it was in 1953 and, if the incidence of tuberculosis continues to decline, will decrease still further. Recent studies ${ }^{11-13}$ have sought to estimate not only the present and future benefits from the national scheme but also its costs (in the widest sense) to provide a rational basis for deciding how much longer large-scale routine BCG vaccination at the age of 10-13 should continue in Great Britain.

The trial reported here was under the general direction of the Medical Research Council's Tuberculosis Vaccines Clinical Trials Committee, which was set up in 1949 and disbanded in 1973 (Chairman: Dr P D'Arcy Hart; Secretary: Dr Marc Daniels, until his death in 1953; Dr T M Pollock, until 1960; then Dr Ian Sutherland). The work was carried out primarily by the Council's Tuberculosis Research Unit (now Tuberculosis and Chest Diseases Unit) in cooperation with their Statistical Research Unit (now Statistical Research and Services Unit).

The membership of the Committee at different times, together with detailed acknowledgments to those who helped in the early stages of the trial and throughout the 20 years' follow-up, appears at the end of the four previous reports. Dr V H Springett served throughout as the principal independent assessor. The clerical work during the closing stages has been the responsibility of Mrs A Smith (MRC Statistical Research and Services Unit).

\section{References}

1 Medical Research Council, British Medical fournal, 1956, 1, 413.

2 Medical Research Council, British Medical fournal, 1959, 2, 379.

3 Medical Research Council, British Medical fournal, 1963, 1, 973.

4 Medical Research Council, Bulletin of the World Health Organisation, $1972,46,371$.

5 Comstock, G W, Livesay, V T, and Woolpert, S F, American fournal of Public Health, 1974, 64, 283.

${ }^{6}$ Comstock, G W, Woolpert, S F, and Livesay, V T, Public Health Reports (Washington), 1976, 91, 276.

${ }^{7}$ Hart, P D'A, British Medical fournal, 1967, 1, 587.

8 Sutherland, I, in Fogarty International Center Proceedings, No 14, 113-125. Washington, DC, Department of Health Education and Welfare, 1972.

o ten Dam, H G, et al, Bulletin of the World Health Organisation, 1976, 54, 255.

10 Springett, V H, and Sutherland, I, British Medical fournal, 1970, 4, 148.

11 British Thoracic and Tuberculosis Association, Tubercle, 1975, 56, 129.

12 Springett, V H, Postgraäuate Medical fournal, 1976, 52, 584.

13 Stilwell, J A, British Medical fournal, 1976, 1, 1002. 